Nuntius Antiquus, Belo Horizonte, v. 11, n. 2, p. 83-98, 2015

\title{
Aristóteles, a tragédia e as emoções de medo e esperança ilustradas nos filmes Una voce umana de R. Rosselini e Mãe e filho de A. Sokurov
}

\section{Aristotle, tragedy and the emotions of fear and hope illustrated in the films A Human Voice of R. Rosselini and Mother and Son of A. Sokurov ${ }^{1}$}

Fernando Rey Puente

Faculdade de Filosofia e Ciências Humanas da UFMG ferey99@yahoo.com.br

Resumo: $\mathrm{O}$ texto tem como objetivo apresentar algumas reflexões sobre a tragédia (e a desconsideração de sua dimensão musical) em Aristóteles, bem como comparar os distintos modos de expectativa (elpis) - o medo (phóbos) e a esperança (thársos) - com dois filmes, um de Rosselini e outro de Sokurov, que se utilizam dos recursos musicais para apresentar as emoções de suas personagens e nos quais as histórias de seus respectivos protagonistas retratam muito bem essas duas diferentes expectativas diante do futuro iminente: o medo e a esperança.

\footnotetext{
${ }^{1}$ Texto apresentado no evento "I Seminário Docere, Delectare et Mouere: Emoções Aristotélicas no Cinema" (Centro de Convenções do Complexo Santuário do Caraça, na região da cidade de Santa Bárbara, Minas Gerais, de 10 a 13 de março de 2015, <www. letras.ufmg.br/doceredelectareetmovere>) organizado por Maria Cecília de Miranda Nogueira Coelho (Departamento de Filosofia da FAFICH-UFMG), como coordenadora geral, e por Helcira Maria Rodrigues de Lima, Sérgio Alcides Pereira do Amaral e Teodoro Rennó Assunção (todos três da FALE/UFMG), e promovido pelo Grupo de Pesquisa "Retórica e Argumentação", do CNPq e UFMG (FAFICH-FALE), pelo "Núcleo de Estudos Antigos e Medievais" (NEAM) do CNPq e UFMG (FALE-FAFICH), com apoio da CAPES, da FAPEMIG, do PPG-FIL da FAFICH/UFMG, do PÓS-LIN e do PÓS-LIT da FALE/UFMG.
} 
Palavras-chave: emoções; tragédia; expectativa; Aristóteles; Rosselini; Sokurov.

Abstract: The text aims to present some reflections on the tragedy (and the disregard of its musical dimension) in Aristotle as well as to compare the different modes of expectation (elpis) - fear (phóbos) and hope (thársos) - with two films, one of Rosselini and another of Sokurov, which use musical resources to present the emotions of their characters and in which the stories of their respective protagonists illustrate very well these two different expectations before the imminent future: fear and hope.

Keywords: emotions; tragedy; expectation; Aristotle; Rosselini; Sokurov.

Recebido em 22 de julho de 2015

Aprovado em 7 de setembro de 2015

Poderia Aristóteles nos ajudar a entender o cinema? O propósito deste texto é o de apresentar de modo exploratório alguns problemas que serão tratados ao propormos uma analogia entre a obra do estagirita e dois filmes que analisaremos brevemente. Um primeiro problema diz respeito ao modo como Aristóteles entende a tragédia grega na Poética e a como ele desconsidera em sua análise da mesma o elemento rítmico e cênico das tragédias. Isso é estranho, pois na Política ele menciona claramente a importância da música. Fica então sem resposta, no âmbito deste texto, a questão que levantamos de saber por que o estagirita não leva em conta essa dimensão musical e cênica quando analisa a tragédia grega, dado que sabemos o quanto a música e a encenação eram fundamentais para a vivência do teatro grego. Ora, nos dois filmes sobre os quais falaremos, um de Rosselini e o outro de Sokurov, constataremos a importância da música, ${ }^{2}$ especialmente no filme de Sokurov, em que parece realmente ser um veículo ideal para a transmissão das emoções, como Aristóteles reconhecia na Política, embora não tenha se dedicado a verificar como isso ocorreria na sua investigação acerca das tragédias realizada na Poética.O outro problema que pretendemos explorar está relacionado à Retórica, obra na qual o estagirita refletiu sobre as

\footnotetext{
${ }^{2}$ Sobre a importância da música no cinema consultar o texto já clássico de A. J. Cohen (2001, p. 249 -272).
} 
emoções. Individuaremos dentre as muitas emoções descritas uma delas, a saber, a expectativa diante do futuro iminente, dado que os dois filmes que comentaremos neste texto, apesar de em uma primeira análise tão diversos do ponto de vista do enredo, estão alicerçados no modo como essa expectativa (elpís) diante do futuro próximo é vivido por seus protagonistas (seja a mulher abandonada por seu amante em Una voce umana, seja o filho que perde a mãe doente em Mãe e filho). Poderemos averiguar então que essas duas modalidades de vivenciar o futuro, bem descritas por Aristóteles na Retórica, podem servir para explicitar as duas respostas diversas ilustradas pelos protagonistas desses dois filmes: o medo (phóbos) que acomete a mulher abandonada e a esperança (thársos) que acompanha o filho que presencia a morte de sua mãe.

\section{Aristóteles, as emoções, a tragédia e a música}

Nesta seção, começamos a refletir sobre o modo como Aristóteles se aproxima daquilo que nós denominamos emoções, e que ele denominava de páthe.

Quando nós pensamos que as emoções enumeradas e descritas no segundo livro da Retórica têm como principal fonte de exemplos a literatura grega, poderíamos pensar que a célebre definição aristotélica da tragédia, contida na Poética, ${ }^{3}$ fosse uma análise fiel das tragédias que ele teria assistido em Atenas, mas a ênfase que Aristóteles confere em sua análise ao enredo (mythos) em detrimento da melopoíia (a melodia) - a qual para ele é o principal ornamento (literalmente Aristóteles fala em sua definição de um discurso agradável (hedysménoi lógoi $i)^{4}$ da tragédia que ele entende como um discurso provido de ritmo e harmonia) - e do espetáculo cênico (ópsis) (fator que ele reconhece como sendo o mais psychagogikón, ou seja, o que causa a maior comoção anímica nos espectadores), mostra que estamos diante de uma análise bastante particular da tragédia que lida principalmente com o texto e não com o espetáculo visual e musical envolvido na encenação dramatúrgica do mesmo. A partir desta constatação, podemos então especular se o

\footnotetext{
${ }^{3}$ ARISTÓTELES, Poética $1349 \mathrm{~b}$ 24-28.

${ }^{4}$ Segundo a análise de Sifakis (2001, p. 58-59), na tragédia o elemento musical ajuda a revelar as "ethical qualities and emotions that lie beyond the limits and expressive capabilities of ordinary speech".
} 
estagirita teria condições de interpretar um filme quase sem enredo, ou cujo enredo minimalista fosse constituído eminentemente pela dimensão visual e musical nele presentes, precisamente aquelas partes da tragédia (a música e a encenação) - aceitando uma possível comparação obviamente anacrônica entre produções culturais tão diversas como a tragédia grega clássica e o cinema contemporâneo - desconsideradas em seu estudo da tragédia.

É curioso constatar, contudo, que Aristóteles reconhece a importância da música na formação dos cidadãos e, por isso, no livro oitavo de sua Política, considera que a música deverá fazer parte da educação dos jovens. Ele justifica essa inserção da música ao ressaltar que ela não é algo necessário, nem mesmo útil, e que, devido a isso, ela seria digna de preencher o ócio dos homens livres (cf. Pol. VIII 1338a 13-24). Após essa breve menção, o estagirita dedica os três últimos capítulos do livro VIII à análise da música no processo de formação dos jovens cidadãos. Nesses capítulos, Aristóteles tece importantes considerações acerca da música e de sua influência no que diz respeito às emoções e à formação dos caracteres. Para além de causar prazer em todos os homens, o estagirita quer saber se a música contribui de fato para a formação da alma e para a constituição do caráter de um homem. E, de modo surpreendente, tendo em vista o trecho da Poética que acabamos de mencionar acima, encontramos nas palavras do próprio Aristóteles na Política (1340a 19-25) o seguinte elogio à música e à sua relação com as emoções:

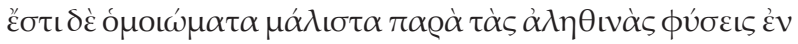

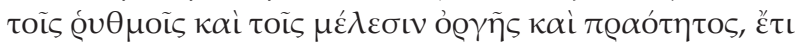

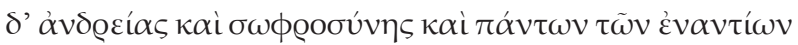

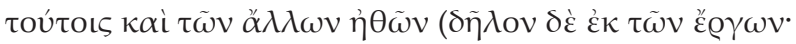

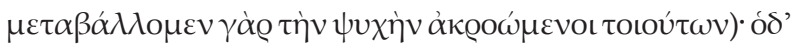

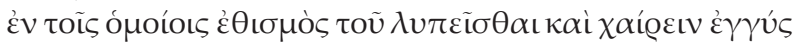

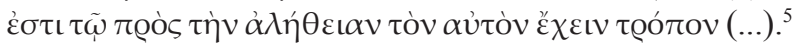

5 "É precisamente nos ritmos e nas melodias que nos deparamos com as imitações mais perfeitas da verdadeira natureza da cólera e da mansidão, e também da coragem e da temperança, e de todos os seus opostos e outras disposições morais (a prática prova-o bem, visto que o nosso estado de espírito se altera consoante a música que escutamos). A tristeza e a alegria que experimentamos através das imitações estão muito perto da verdade desses sentimentos (...)". (trad. António Campelo Amaral e Carlos de Carvalho Gomes) 
Dado que - continua Aristóteles - existem distintas melodias, ocorre uma reação análoga à estrutura de cada uma delas na alma de quem as escuta, de modo que a melodia mixolídia, por exemplo, produz melancolia, outras produzem um estado de espírito intermédio e circunspecto como a dórica, e a frígia, por fim, induz ao entusiasmo. O mesmo sucede com os ritmos que podem ser mais calmos ou mais céleres e induzir consequentemente os ouvintes a estados de alma mais serenos ou mais agitados.

Aristóteles também menciona que certos instrumentos musicais não são propícios à educação, como o aulós, um instrumento parecido com o nosso oboé, pois este impede a fala, sendo mais adequado então para a elaboração de um espetáculo que visa a produzir uma purificação e não um aprendizado. Ora, com isso o estagirita reconhece, como ele afirma mais adiante, que a música (mélos) "não deve ser aprendida apenas porque promove uma disposição benéfica, mas sim muitas; na verdade, o seu uso refere-se não só à prática educativa como à catarse". ${ }^{6}$

$\mathrm{Na}$ frase seguinte, Aristóteles remete à Poética onde, segundo afirma nesse trecho da Política, tratará de modo mais detalhado, sem fazer maiores especificações, do que ele denomina catarse. Infelizmente, como se sabe, em seu tratado sobre a tragédia, ele nada acrescenta sobre o significado de catarse, a não ser que a tragédia produziria essa purificação das emoções em seus espectadores. ${ }^{7}$

O que é importante se perguntar então é porque, se Aristóteles reconhece a importância da música nessas páginas da Política, ele silencia sobre sua importância na análise que nos oferece da tragédia. Igualmente, seria interessante meditarmos sobre o fato de que o tratamento das emoções na Retórica parece ser bastante diverso do tratamento educativo ou mesmo catártico aludido em um trecho da Política e corroborado em uma passagem da Poética. Poderíamos nos indagar então se, por exemplo, seria a mesma orgé que estaria sendo produzida pelo discurso do bom orador em seus ouvintes, que estaria sendo aprendida pelos jovens graças ao ensino da música, ou que provocaria a purificação das emoções nos espectadores quando encenada em um espetáculo teatral que sintetizaria

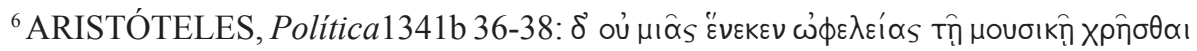

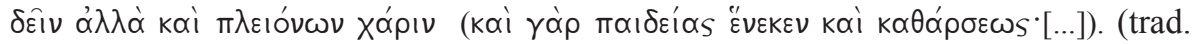
António Campelo Amaral e Carlos de Carvalho Gomes)

${ }^{7}$ Sobre esse tema remetemos ao nosso estudo (PUENTE, 2002, p. 10-27).
} 
enredo, música e espetáculo cênico. Essas e outras conjecturas podem ser feitas, mas, infelizmente, dado a escassez de textos de Aristóteles e ao caráter elíptico das passagens sobre a catarse contidas na Poética e na Política, não poderão jamais ser respondidas com algum apoio textual nos textos do próprio Aristóteles, ou mesmo por meio de uma comparação com as tragédias que chegaram até nós, dado que nos é praticamente impossível imaginar, por mais que hoje em dia tenhamos reconstituições criteriosas da mesma, como efetivamente a música grega, com suas melodias e seus ritmos, soaria. Mais ainda: como esses ritmos e melodias compunham juntamente com o enredo - especialmente importante para Aristóteles - a tragédia grega. ${ }^{8}$

Essa dificuldade em apreciar corretamente a dimensão musical da tragédia grega, cabe enfatizar, é para nós uma perda muito mais grave ainda do que o fato de imaginarmos o mundo arquitetônico e estatuário das cidades gregas da era clássica em austeros tons de cinza e branco, pois neste caso várias reconstituições cromáticas podem ser simuladas por computador a partir de micropigmentos de cores detectadas em diversas estátuas e ruínas de templos e podemos, assim, reconstituir com bastante precisão como estátuas, templos e casas eram coloridos na Antiguidade grega. ${ }^{9}$ As melodias e os ritmos do mundo grego, contudo, sendo de natureza muito mais evanescente, não teriam como deixar vestígios sonoros e, devido a isso, apesar dos esforços de reconstrução atuais da música grega clássica, esta se perdeu para sempre. ${ }^{10}$

8 Sobre a tragédia grega e sua relação originária com a música consultar o item "Music in the Theatre" do capítulo "Musical Life in Ancient Greece" do minucioso e alentado volume de Thomas Mathiesen (1999, p. 94-125), em cujas páginas o autor descreve minuciosamente todo o festival no interior do qual as tragédias e comédias eram apresentadas e esclarece a importância do coro e da música no âmbito da tragédia. ${ }^{9}$ Sobre o estudo da cor na Antiguidade consultar o livro organizado por Rolf Kuehni e Andreas Schwarz (2007) e especialmente o livro organizado por R. Panzanelli, E. Schmidt e K. Lapatin (2008, p. 18-39), particularmente o capítulo "The Polychromy of Ancient Greek Sculpture" de Vinzenz Brikmann.

${ }^{10}$ Sobre o que restou em termos de manuscritos da música grega conferir o erudito livro de E. Pöhlmann e M. L. West (2001). Sobre a melhor tentativa de reconstrução musical da música da Grécia clássica vale a pena acompanhar a obra (escrita e musical) da musicista e helenista Annie Bélis, que tem procurado reconstruir, na medida do possível, a música da Antiguidade Clássica. 
Feitas essas observações iniciais sobre Aristóteles, a tragédia e a música, passemos à ideia central deste texto, qual seja, a de propor uma comparação entre dois filmes cujo tema central se articula em torno de duas esperas vividas de modo muito diverso, com um enredo minimalista (uma mulher abandonada pelo amante que espera ansiosamente por um telefonema dele e que com ele dialoga pela última vez; e um filho e sua velha mãe que esperam com calma e serenidade pela morte próxima desta) e com a utilização de recursos distintos para produzir as emoções aqui em análise. Posteriormente, retornaremos a Aristóteles, desta vez analisando os dois modos - o medo (phóbos) e a confiança (thársos) como a expectativa ante o futuro próximo pode ser concebida a partir de suas reflexões sobre as emoções.

No primeiro filme, estamos diante de um claro projeto do que identificamos neste texto como a verbalização das emoções. Isto ocorre por meio de um monólogo que explicita as diversas fases de desespero de uma mulher abandonada pelo amado e que, apesar de tudo, não consegue deixar de amá-lo profundamente. No segundo filme, estamos diante de uma obra com poucos e breves diálogos entre uma mãe moribunda e seu atento e dedicado filho. Permeando essas duas personagens, contudo, há um mundo de emoções insinuadas e sugeridas por meio da música e da bela fotografia criando, assim, uma atmosfera capaz de, sem proceder a uma verbalização das emoções entre mãe e filho, evocar a ternura, a delicadeza e o amor existente entre eles.

\section{Una voce umana de Rosselini (Cocteau) ou a verbalização das emoções}

A filmagem de Roberto Rosselini de uma célebre peça de Jean Cocteau (1889-1963), La voix humaine, que foi escrita em 1930 e protagonizada no mesmo ano na Comédie-Française por Bertha Bevy a quem, na verdade, Cocteau pretendia homenagear com essa peça, é o filme que escolhemos para evidenciar o que significa a verbalização das emoções. Essa obra de Cocteau teve inúmeras transposições posteriores, seja para o domínio operístico (por exemplo: a ópera cômica de Gian Carlo Menotti, Le Téléphone, composta em 1946 e a ópera homônima de Francis Poulanc composta em 1958), seja para o domínio cinematográfico (com R. Rosselini em 1948) ou obviamente teatral e televisivo, tendo como protagonistas excelentes atrizes como Ingrid Bergman em 1966, 
Simone Signoret em 1964 e Liv Ullmann em 1979. No Brasil, cabe mencionar a inauguração do Teatro Brasileiro de Comédia no ano de 1948 em São Paulo, cuja peça de estreia foi precisamente $A$ voz humana de J. Cocteau, interpretada no original pela atriz francesa, radicada no Brasil desde os anos 30, Henriette Morineau.

O episódio intitulado Una voce umana, interpretado de modo inesquecível por Anna Magnani no filme Amore de Roberto Rosselini, pode ser pensado na verdade como um monólogo - dado que nunca chegamos a ouvir claramente o amante que fala ao telefone com a mulher sequiosa de ouvir a voz do mesmo uma última vez - monólogo desesperado de uma mulher que literalmente tenta se agarrar ao telefone como se literalmente sua vida estivesse suspensa sobre um abismo apenas por um tênue fio.

O episódio pode ser dividido, de modo geral, em duas partes. Em ambas presenciamos uma mulher insegura, à beira do desespero e muito ansiosa esperando receber um telefonema do amante que a deixou. Na primeira parte do filme, ela, apesar de totalmente nervosa, inquieta, desanimada e triste, tenta se apresentar como forte e corajosa para o amante. Ela lhe diz que, naquele mesmo dia em que ele a havia deixado, passeara com uma amiga, enfim, mente afirmando ter tido um dia normal e que estava lidando bem com o rompimento da relação entre eles. Essa situação fictícia perdura até a ligação telefônica ser interrompida e ela ficar ainda mais insegura, o que ocorre aos dezesseis minutos do filme, mais ou menos a metade da filmagem que dura ao todo cerca de trinta e dois minutos. Ela resolve então telefonar para a casa do amante, supondo que ele estivesse no apartamento que dividia com um amigo. Surpresa com o fato de ele não se encontrar lá, ela fica ainda mais ansiosa esperando que o amante volte a telefonar para ela. Aos dezesseis minutos e quarenta e cinco segundos, entra um tema musical triste que parece explicitar ainda mais a angústia desta mulher. Ela não sabe o que fazer, levanta, caminha, se olha nos espelhos de seu quarto. Está completamente perdida e consciente de sua solidão. Para contrapor o estado de agitação e inquietação dela com o exterior, aos dezoito minutos do filme passamos a ouvir uma música alegre vinda dos apartamentos vizinhos, risos, choro de crianças, enfim, a vida esfuziante que está ao mesmo tempo tão perto e tão distante do vazio e desespero dessa mulher abandonada que nem ao menos consegue dormir para esquecer sua solidão. Aos dezenove minutos e quinze segundos, o telefone toca 
novamente. A vida ressurge para ela. Desta vez, contudo, a conversa com o amante ao telefone é outra. Ela chora, pede perdão e lhe revela que até aquele momento havia mentido ao telefone para ele. Na verdade, o que ela quer mesmo é que ele seja honesto e confesse que lhe havia mentido ao dizer que estava no apartamento que dividia com um amigo, mas não tem coragem de lhe dizer isso e deste modo confessa apenas que mentiu para ele, esperando, porém, que ouvindo a sua confissão ele igualmente resolva contar a verdade. Diz-lhe então que ela não havia saído de casa naquele dia, que não havia conseguido dormir, que ingeriu medicamentos para tentar dormir e que chegou até mesmo a pensar em se matar, confessando finalmente ao seu amante: "Respiro porque falo com você!" Ela não aguenta mais e, ante as mentiras que ele lhe conta, em uma profunda crise de ciúme, diz que ele não dormiu no apartamento que divide com o amigo, que não lhe havia dito a verdade. Mas, sob a ameaça de ele desligar o telefone, ela então implora que ele não faça isso e afirma que ela passou toda a sua vida esperando por ele e que se ele interromper a ligação telefônica, ela morrerá de culpa. Explica que as pessoas em geral só entendem relações de amor ou de ódio e não relações, como a deles, de amor/ódio ou de ódio/amor. Ela não resiste, porém, a sua intenção mais íntima e, a fim de provocar a desejada confissão do amante, começa a formular no condicional a seguinte questão: imagine que você estivesse mentindo, que tivesse dito estar em casa sem de fato estar em sua casa... Nesse momento, sem suportar mais a cobrança ciumenta por parte dela, ele desliga. Ela se exaspera. Começa a implorar a Deus que ele ligue de novo. Acredita que ele está próximo do apartamento dela e, ao ouvir o som de uma porta se abrindo e de alguém subindo as escadas em seu prédio, implora diversas vezes a Deus que seja ele. Por fim, ao perceber que realmente não era seu amante, ela começa a chorar desesperadamente. Finalmente o telefone volta a tocar. Ela se descontrola e afirma que o odeia, mas imediatamente se corrige: "Te amo, te amo, te amo". Assim, proferindo esse voto de um amor impossível, estendida na cama, desfalecida, ouvimos novamente nos segundos finais do filme uma música trágica parecendo exprimir melhor ainda do que as palavras o desespero e a angústia dessa solitária mulher perdidamente apaixonada por um homem que ela sabe que jamais verá novamente. 


\section{Mãe e filho de Sokurov ou a insinuação das emoções}

O filme minimalista ${ }^{11}$ de Alexander Sokurov pode ser dividido em cinco grandes momentos: o início da narrativa, quando é mostrado que mãe e filho vivem um profundo estado de comunhão, o que se evidencia pelo fato de eles terem tido o mesmo sonho. O filho começa a contar o seu sonho e a sua mãe continua a narrativa. Enquanto isso, ele fica penteando-a na cama com muita delicadeza. Ela lhe diz então que quer ir passear. Ele adverte que está frio e que ela deveria comer, mas ela insiste em sair, em ir passear. Nesses dez minutos iniciais do filme, há curtos diálogos entre mãe e filho, mas é a atmosfera de doçura e o clima de delicadeza mostrado pelas imagens, e ressaltados pela suave e doce música de fundo, que dão o tom dessa relação idílica que há entre os dois.

O segundo momento do filme é marcado pelo passeio dos dois. Trata-se de uma imersão do filho e da mãe na natureza. Ele a carrega com ternura e atenção até deitá-la em um banco; então ele se ausenta para ir buscar na casa umas fotos antigas que encontrou e que quer mostrar para ela. Ao regressar percebe que sua mãe está dormindo. Ele a contempla com muito carinho e apoia delicadamente a cabeça frágil da mãe adormecida em seu braço, que utiliza como se fosse um travesseiro. Alisa delicadamente os cabelos da mãe. Subitamente a dor irrompe no filme: a mãe geme, se contorce, agoniza. O semblante de impotência e desespero do filho se evidencia. Ele a apoia, mas não pode fazer nada para aliviar a dor da mãe. Ela melhora. Ele a carrega de novo e passeia com ela em seus braços. A inversão de papéis é evidente. Ele parece o pai dela. Ela, um bebê frágil e desprotegido. Ele, um gigante que a carrega como se ela nada pesasse. Essa parte do filme dura mais ou menos uns vinte e cinco minutos. Há várias paradas no passeio e curtos diálogos entre mãe e filho, mas predomina uma atmosfera idílica expressa pela paisagem que parece irreal. Uma paisagem claramente inspirada em quadros do grande pintor do romantismo alemão Caspar David Friedrich e de outros mestres da pintura. ${ }^{12}$ Aos vinte e dois minutos o filho, contemplando a natureza, exclama: "A criação é maravilhosa". É com esse mote da beleza da criação e da fragilidade do ser humano que nela habita que podemos

\footnotetext{
${ }^{11}$ Sobre o minimalismo de Sokurov, cf. artigo de S. Hänsgen (2011, p. 43-56).

${ }^{12}$ Sobre a importância de alguns mestres da pintura como Caravaggio, Rubens, Rembrandt e especialmente Friedrich (que Sokurov mesmo explicitamente menciona), cf. o capítulo sobre este filme no livro de Jeremi Szaniawski (2013, p. 126-138).
} 
caracterizar essa parte do filme. Ele para de novo e apoia a mãe em uma árvore. Nesse momento ele lhe diz: "É bom viver aqui!", mas a mãe lhe responde: "É bom, mas é de algum modo opressivo". O passeio continua até que ele, carregando-a com extrema ternura nos braços, beija a testa da mãe e a balança em seu colo como se estivesse ninando uma criança.

Aos trinta e cinco minutos do filme, inicia-se o que podemos pensar como sendo a sua terceira parte. Nesse momento o passeio acaba, o filho entra na casa novamente, e senta a sua mãe em uma cadeira, dando-lhe de beber com uma mamadeira. Ele fica em pé e a admira compassivamente. A seguir, ele a deita na cama. Ela fica olhando para ele com tristeza e ele, por sua vez, contempla-a com piedade. Então, em um movimento vital, ela quer olhar a paisagem pela janela do quarto. Nesse momento acontece um dos curtíssimos diálogos do filme que reproduzimos abaixo:

Mãe: "Tenho medo da morte".

Filho: "Não morra, quem te obriga a morrer?"

Mãe: "Você!"

Filho: "Você pode viver quanto quiser".

Mãe: "Para quê? Para quê?"

Filho: "Para nada em especial. Mas morre-se por uma razão".

Mãe: "Qual a minha? Não tenho".

Filho: "Goze a vida!"

Mãe: "Não quero que chegue a primavera".

O filho preocupado se pergunta: "O que fazer contigo? Não quer comer, não quer dormir... Olhe o jardim, está em flor!” Nesse momento a suave música de fundo enfatiza ainda mais do que o diálogo desencontrado a dor da despedida iminente. O filho afirma: "Você e eu nos adoramos". A mãe segura uma borboleta entre seus dedos e sorri. O que se passa a partir daí não fica claro, pois é propositalmente apenas insinuado.

O que vemos aos quarenta e nove minutos do filme é que o filho está mais uma vez fora de casa. E aqui podemos assinalar que se inaugura o quarto momento do filme. Agora ele caminha só na natureza. Deixou a mãe dormindo? Saiu quando ela contemplava a borboleta entre os dedos de sua mão para não perturbá-la? Saiu para não presenciar a 
morte de sua mãe? Ou para que ela pudesse partir na sua ausência? Não temos certeza. Vemos apenas que agora ele anda por caminhos íngremes e que seu corpo, que antes vimos como grande e forte em relação ao corpo delicado de sua mãe, é minúsculo e frágil ante a grandiosidade da natureza que o circunda. Ele caminha ao lado de um córrego, se deita, o Sol incide sobre ele. Levanta e continua errando entre frondosas árvores. Até que, quase dez minutos depois dessa longa e demorada caminhada, ele se apoia em uma frondosa e imponente árvore e começa a chorar e gemer, o que dura uns dois minutos. Aos sessenta e um minutos do filme, ele finalmente regressa a sua casa.

Estamos, por fim, na última parte do filme e aquela que tem a mais curta duração. Em apenas cinco minutos ocorre o esperado ao longo de todo o filme: a morte da mãe. O filho, ao entrar na casa, olha para a mãe. Estaria ela apenas dormindo ou o inevitável teria ocorrido? Ele acaricia a mão dela, assopra a borboleta que ainda estava lá pousada entre seus dedos. Um símbolo de um resquício da vida que não queria deixar aquele frágil corpo? A delicadeza de não mostrar o momento da morte da mãe e ao mesmo tempo o fato de pôr em destaque a frágil borboleta é uma clara marca da atmosfera predominante ao longo de todo o filme. Alude-se e não se afirma. Insinua-se, sugere-se e quase nunca se mostra. O filho se recosta sobre o corpo morto de sua mãe. Seus dedos tocam delicadamente nos dedos dela. Uma mão quente e viva, a outra, fria e morta. Ele grita e chora. Por fim, ele faz a derradeira promessa a sua mãe ao dizer: "Nós nos encontraremos no lugar combinado. Espere por mim. Tenha paciência". E com a palavra paciência, a mesma que o espectador teve de ter para ver este filme lento e quase sem nenhuma ação, o filme termina.

\section{A expectativa diante do futuro: temor (phóbos) e confiança (thársos)}

Aristóteles, em seu tratado sobre a memória, afirma muito claramente que esta é relativa ao passado, tal como a percepção é relativa ao presente e a expectativa relacionada ao futuro (De mem. $449 \mathrm{~b}_{25-27}$ ). Note-se que aqui elpís possui claramente um valor neutro significando apenas o abrir-se ante o devir, sem levar em conta os casos em que a relação com o futuro é positiva ou negativamente avaliada.

O que esses dois filmes nos mostram então é, não apenas duas maneiras distintas de exprimir as emoções - verbalizando-as tanto quanto 
possível ou silenciando-as o mais das vezes -, mas também diferentes modos de viver a expectativa. Esses modos diversos de vivenciar a expectativa ante um fato iminente - a espera por um telefonema do amado ou a morte iminente da mãe - estão obviamente ancorados nas emoções, pois, como Aristóteles nos mostra na Retórica $\left(1378 \mathrm{a}_{19-20}\right)$, os páthe são mudanças (metabálontes) nas pessoas que causam alteração de seus juízos (kríseis).

Podemos então tentar entender essas diferentes formas de expectativa em relação ao devir a partir do capítulo cinco do segundo livro da Retórica no qual Aristóteles analisa o temor (phóbos) e a confiança (thársos) que entende como contrários. Como ambos estão relacionados a essa expectativa ante o futuro próximo, os dois filmes em questão se prestam bem à averiguação de saber se, e em que medida, nós podemos compreender a expectativa da amante e a confiança do filho a partir dessas considerações contidas neste capítulo do segundo livro da Retórica.

Uma passagem interessante desse capítulo coloca em evidência o caráter futuro do temor, pois para temer, afirma o estagirita: "É preciso guardar no íntimo alguma esperança de salvação, com respeito àquilo pelo que se luta". ${ }^{13}$ Ora, no filme de Rosselini essa esperança fica claramente ilustrada quando a amante acredita que seu amado voltou. Ou seja: ela ainda guarda alguma esperança que o amante possa voltar, caso contrário, não experimentaria mais temor, tal como ocorre com aqueles que nas palavras de Aristóteles "creem já terem sofrido todas as coisas temíveis e se tornaram indiferentes ao futuro". ${ }^{14}$

De certo modo, portanto, parece-nos que o temor expresso pela ansiedade e angústia da amante, que está ciente de ter sido deixada para sempre, pode ser referido a essa experiência de que fala Aristóteles nessas passagens da Retórica. Mas e a confiança do filho ao aguardar com serenidade a morte da mãe no filme de Sokurov? Podemos compreendê-lo com a ajuda desse capítulo? Pensamos que isso é parcialmente possível, porém, em outro capítulo deste mesmo livro da Retórica, acreditamos que o estagirita se aproxima um pouco mais dessa experiência do filho no filme de Sokurov. A atitude do filho para Aristóteles seria a atitude

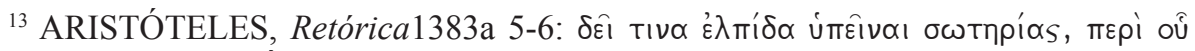

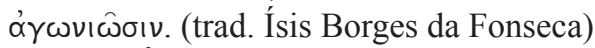

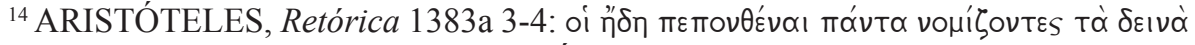

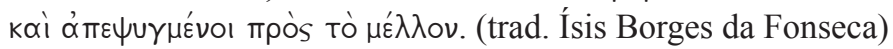


típica de um jovem, tal como ele a descreve no capítulo doze do segundo livro da Retórica (1389 a21-29), a saber:

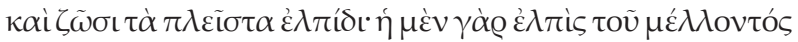

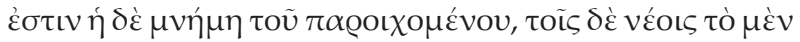

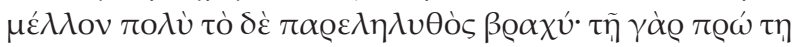

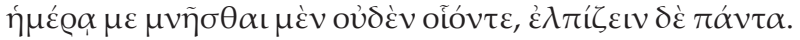

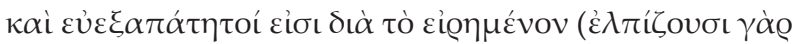

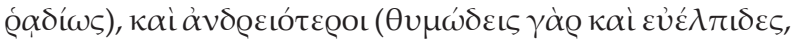

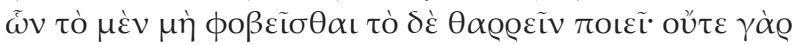

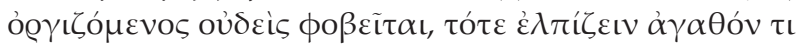

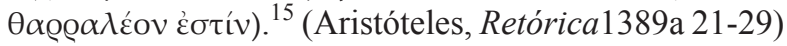

Algumas passagens do filme onde ocorrem breves diálogos entre ele e a mãe parecem opor realmente a visão otimista do filho ao olhar mais pessimista da mãe, olhar típico de um idoso para Aristóteles. Assim, é o filho que afirma a beleza da natureza, é ele que diz que sua mãe não precisa morrer e é igualmente ele que afirma que é bom viver. Nesse contexto, podemos entender que a confiança está intimamente ancorada na sua esperança pelo bem (elpízein agathón). Todavia, a esperança de que parece se alimentar o filho é muito mais do que uma mera confiança alicerçada em pura ingenuidade e aqui nos movemos em um território onde Aristóteles não conseguiu ou não quis penetrar, assim como não o fez em relação à música no âmbito da tragédia, a saber, a religiosidade. A esperança do filho parece estar fundamentada em sua religiosidade, pois, como o fim do filme nos indica, ele espera poder reencontrar sua mãe alhures. Ingenuidade proveniente da falta de experiência ou certeza ancorada na fé? Lembremos, porém, que o filho afirma com muita ênfase para a sua mãe: "Eu sou muito racional". Essa espiritualidade, portanto, não é avessa à razão, mas a complementa, algo que assinala a relação de

\footnotetext{
15 "A maior parte dos jovens vive da esperança, porque a esperança concerne ao futuro, ao passo que a lembrança diz respeito ao passado; para a juventude, o futuro é longo e o passado curto; na verdade, no começo da vida nada há para recordar, tudo há a esperar. Pelo que acabamos de dizer, os jovens são fáceis de enganar (é que facilmente esperam), e são mais corajosos [do que noutras idades], pois são impulsivos e otimistas: a primeira destas qualidades fá-los ignorar o medo, a segunda inspira-lhes confiança, porque nada se teme quando se está zangado e o fato de se esperar algo de bom é razão para ter confiança". (trad. Manuel Alexandre Júnior, Paulo Farmhouse Alberto e Abel do Nascimento Pena)
} 
Sokurov com uma dimensão espiritual e que, evidentemente, está muito distante de Aristóteles.

Gostaria de agradecer à bolsa Pesquisador Mineiro da Fapemig pelo apoio recebido, bem como ao colega da FALE-UFMG, prof. Dr. Teodoro Rennó Assunção, pelas correções e sugestões ao texto.

\section{Referências}

ARISTOTELE. L'anima e il corpo; Parva Naturalia (testo greco a fronte). Introduzione, trad. e note di Andrea Carbone. Milano: Bompiani, 2002.

ARISTÓTELES. Poética. Trad., prefácio, introdução, comentário e apêndices de Eudoro de Sousa. Lisboa: Imprensa Nacional/Casa da Moeda, 1992 ( $3^{\text {a }}$ ed.).

ARISTÓTELES. Poética. Trad., prefácio, introdução, comentário e apêndices de Eudoro de Sousa. Lisboa: Imprensa Nacional/Casa da Moeda, 1992 ( $3^{\text {a }}$ ed.).

ARISTÓTELES. Política. Edição bilíngue, trad. e notas de António Campelo Amaral e Carlos de Carvalho Gomes. Lisboa: Vega, 1998.

ARISTÓTELES. Retórica das Paixões. Introdução, notas e trad. do grego de Isis Borges da Fonseca. São Paulo: Martins Fontes, 2000.

ARISTÓTELES. Retórica. Introdução de Manuel Alexandre Júnior; trad. e notas de Manuel Alexandre Júnior, Paulo Farmhouse Alberto e Abel do Nascimento Pena. Lisboa: Imprensa Nacional/Casa da Moeda, 1998.

COHEN, A. J. Music as a source of emotion in film. In: JUSLIN, P.; SLOBODA, J. (org.). Music and Emotion. Oxford: Oxford University Press, 2001, p. 249 -272.

HÄNSGEN, S. Sokurov's Cinematic Minimalism. In: BEUMERS, B.; CONDÉE, N. (org.). The Cinema of Alexander Sokurov. London: Tauris, 2011, p. 43-56.

KUEHNI, R.; SCHWARZ, A. Color ordered: a survey of color systems from Antiquity to the present. Oxford: Oxford University Press, 2007. 
MATHIESEN, T. Apollos'Lyre: Greek Music and Music Theory in Antiquity and the Middle Ages. Lincoln/London: University of Nebraska Press, 1999.

PANZANELLI, R.; SCHMIDT, E.; LAPATIN, K. The color of life: polychromy in sculpture from Antiquity to the present. Los Angeles: Getty Publications, 2008.

PÖHLMAN, E.; M. L. WEST. Documents of ancient Greek music: the extant melodies and fragments. Oxford: Oxford University Press, 2001. PUENTE, F. R. A "katharsis" em Platão e Aristóteles. In: DUARTE, R. (org.). Katharsis: reflexos de um conceito estético. Belo Horizonte: Editora C/Arte, 2002, p. 10-27.

SIFAKIS, G. M. Aristotle on the Function of Tragic Poetry. Herakleion: Crete University Press, 2001.

SZANIAWSKI, J. The cinema of Alexander Sokurov: figures of paradox. New York: Columbia University Press, 2013. 